\title{
PENGARUH KARAKTERISTIK DEMOGRAFIS (USIA, GENDER,PENDIDIKAN), MASA KERJA DAN KEPUASAN GAJI TERHADAP KOMITMEN AFEKTIF) (Studi Pada Tenaga Paramedik Non-PNS RSUD Kota Semarang)
}

\author{
Simson Hutagalung*, Mirwan Surya Perdhana ${ }^{1}$
}

simsonhutagalung.sh@gmail.com

Jurusan Manajemen Fakultas Ekonomika dan Bisnis Universitas Diponegoro Jl. Prof Soedharto SH Tembalang, Semarang 50239, Phone: +622476486851

\begin{abstract}
The purpose of this research is to extend previous research on employee commitment to their organization within with the measurability and the fitness of the tested and reliable employee commitment scale items in a non-western culture within focus to investigate the effect of demographic characteristic (age, gender, education), tenure and pay satisfaction on affective commitment based background of the phenomena that occur in the commitment of contract paramedical employees at the General Hospital of Semarang.

This research was conducted at the General Hospital of the city with A quantitative approachment.The data collection using five-point Likert scaled questionnaire administered to 75 contract paramedical employees at the General Hospital of Semarang.

The results indicates that there are no significant effect between both demographic characteristic (age, gender, education) and tenure on affective commitment.Conversely, the result indicate there is a positive significant correlation between pay satisfaction towards affective commitment at the General Hospital of Semarang.
\end{abstract}

Keywords: Demographic characteristic (age, gender, education, tenure and affective commitment)

\section{PENDAHULUAN}

Penelitian ini menginvestigasi pengaruh karakteristik demografi, masa kerja dan kepuasan gaji terhadap komitmen afektif. Komitmen organisasi merupakan hal yang penting untuk dipertahankan oleh karyawan dalam melaksanakan pekerjaannya. Tanpa adanya komitmen karyawan tidak akan menyelesaikan tugasnya dengan baik dan sesuai dengan tujuan organisasi. Mayer dan Allen (1993) membagi komitmen organisasi menjadi 3 dimensi pokok yaitu : continuance, normative dan Affective commitment.

Menurut Allen dan Mayer, karyawan yang memiliki komitmen afektif yang tinggi merupakan dimensi yang diprediksi terbaik dalam persepsi dan karakteristik individu yang berpengaruh terhadap pekerjaan (Williamson, Burnett, dan Bartol, 2009).
Komitmen afektif juga digambarkan sebagai hal yang lebih berpengaruh dan dapat menginterpretasikan komitmen secara keseluruhan dibandingkan dimensi lainnya yang dimana sangat berpengaruh terhadap pola perilaku karyawan dalam organisasi dan berpengaruh terhadap organizational outcomes seperti tingkat perputaran karyawan dan tingkat keinginan karyawan keluar dari organisasi (Yi-Ching Chen, Shui Wang, dan Sun, 2012).

Salah satu perspektif pendekatan pada komitmen organisasional adalah pada ikatan afektif karyawan terhadap organisasinya yang mana sudut pandang komitmen organisasional ini tergambarkan pada sebuah kepercayaan yang kuat dan penerimaan atas tujuan dan nilai yang dimiliki organisasi oleh karyawan; keinginan untuk melakukan usaha 
yang lebih dengan mengatasnamakan organisasi; dan keinginan yang kuat untuk menjaga keanggotaan dalam organisasi (Steers, 1977).

Terdapat beberapa faktor yang mempengaruhi komitmen afektif seorang karyawan, diantaranya: karakteristik personal, peran dari pengalaman, elemen struktural, kepemimpinan, kepuasan kerja dan lainnya (Han dkk., 2011). Namun, faktor-faktor tersebut cenderung menjadi faktor independen yang dikembangkan dalam penelitian yang dilakukan di luar negeri dengan menggunakan metode pengukuran negara Barat. Pengukuran tersebut dapat diterima di dalam komunitas peneliti secara umum dalam tingkat validitas dan reabilitasnya, namun untuk dalam aplikasinya hasil pengukuran skala Barat terbukti menghadapi permasalahan di negara bagian Timur (Ogba, 2008). Para peneliti merekomendasikan untuk melakukan penemuan ulang dan modifikasi terhadap pengukuran komitmen atau pengembangan skala baru untuk mengukur komitmen karyawan yang sesuai dengan budaya lokal dan kebutuhan organisasi sebelum diterapkan dalam organisasi negara bagian Timur (Ogba, 2008). Oleh karena itu, penelitian ini menggunakan karakteristik demografis, masa kerja dan kepuasan gaji sebagai konstruk yang membangun penelitian komitmen afektif di Indonesia.

\section{TINJAUAN PUSTAKA \\ Komitmen Afektif}

Komitmen afektif merupakan bagian dari komitmen organisasional yang mengacu kepada sisi emosional yang melekat pada diri seorang karyawan terkait keterlibatannya dalam sebuah organisasi. Terdapat kecenderungan bahwa karyawan yang memiliki komitmen afektif yang kuat akan senantiasa setia terhadap organisasi tempat bekerja, karena keinginan untuk bertahan tersebut berasal dari dalam hatinya. Komitmen afektif dapat muncul karena adanya kebutuhan, dan juga adanya ketergantungan terhadap aktivitas-aktivitas yang telah dilakukan oleh organisasi di masa lalu yang tidak dapat ditinggalkan karena akan merugikan. Komitmen ini terbentuk sebagai hasil yang mana organisasi dapat membuat karyawan memiliki keyakinan yang kuat untuk mengikuti segala nilai-nilai organisasi, dan berusaha untuk mewujudkan tujuan organisasi sebagai prioritas pertama, dan karyawan akan juga mempertahankan keanggotaannya.

\section{Karakteristik Demografi}

Usia adalah salah satu bentuk dari human capital (Yi-Ching Chen dkk., 2012). Dimana, usia menjadi salah satu faktor yang memberikan pengaruh baik terhadap kinerja dan juga komitmen organisasional seorang karyawan dalam organisasi. Dalam penelitian Meyer dan Allen mengenai komitmen organisasi sebelumnya dikatakan bahwa pekerja lebih berkomitmen karena mereka lebih merasa mengalami kepuasan yang lebih tinggi di tingkat usia yang lebih tua.

$$
\text { Peran dan hubungan gender }
$$

berkembang dari interaksi yang terjadi antara berbagai kendala biologis, teknologi , ekonomis, dan kendala-kendala sosial lainnya (World Bank, 2005). Berdasarkan penelitian yang dilakukan oleh Angle dan Perry (1981) dan Opayemi (2004) menemukan bahwa wanita lebih berkomitmen terhadap organisasi jika dibandingkan dengan pria (Poopola, 2009).

Pendidikan juga merupakan salah satu hal yang mempengaruhi attitudinal commitment dibandingkan dengan behavioural commitment, yang dimana attitudinal commitment dalam hal ini diartikan sebagai komitmen yang menggambarkan dari segi dimensi afektif (Yi-Ching Chen., 2012). Dengan semakin baiknya pengetahuan dan pengalaman intelek yang didapati oleh seorang karyawan ataupun manusia akan membuat tugas dapat dengan mudah dikerjakan dan mampu menghasilkan output yang terbaik.

\section{Masa Kerja}

Masa kerja diartikan sebagai total waktu seorang pekerja dipekerjakan oleh organisasi. Aryee dkk dalam English dkk (2010) mendefinisikan tahapan karir dalam masa kerja dibagi menjadi : masa percobaan (kurang dari dua tahun masa kerja), masa stabilisasi (dua hingga sepuluh tahun masa kerja) dan masa pemeliharaan atau maintenance (lebih dari sepuluh tahun). Terdapat beberapa hal yang mampu mempengaruhi komitmen organisasi yang didapati oleh seorang karyawan, yakni elemen personal berkaitan human capital, 
hingga aktivitas yang berkaitan dengan komitmen itu sendiri. Salah satu dari beberapa faktor yang dapat mempengaruhi tersebut adalah lama kerja atau masa kerja karyawan.

\section{Kepuasan Gaji}

Gaji dikenal dengan berbagai bentuk dalam kompensasi termasuk kompensasi langsung seperti upah; kompensasi noncash seperti keuntungan; jumlah dari peningkatan gaji dan proses dimana sistem kompensasi diberikan (Williams dkk., 2006). Kepuasan terhadap gaji diartikan dengan tingkat dimana seseorang puas terhadap proses dan level pemberian penghargaan materi berbentuk moneter yang diterima dari tempat bekerja baik secara langsung maupun tidak langsung (Ducharme dkk., 2005). Dengan kata lain, kepuasan gaji dapat diartikan dengan total dari efek positif (perasaan) individu terkait dengan gaji/ bayarannya (Kantor, 2013).

\section{Pengaruh Karakteristik demografis terhadap Komitmen Afektif}

Berdasarkan penelitian yang dilakukan oleh Popoola tahun 2009, Socio economic (usia, gender, gaji, kualifikasi pendidikan, dll) menunjukkan hubungan yang positif signifikan terhadap komitmen afektif. Dari beberapa pernyataan penelitian yang dilakukan sebelumnya dapat dikatakan bahwa faktor socio economic dan karakteristik demografi menjadi faktor prediktor yang menjelaskan komitmen afektif suatu organisasi. Berdasarkan pernyataan tersebut dapat dirumuskan hipotesis berikut:

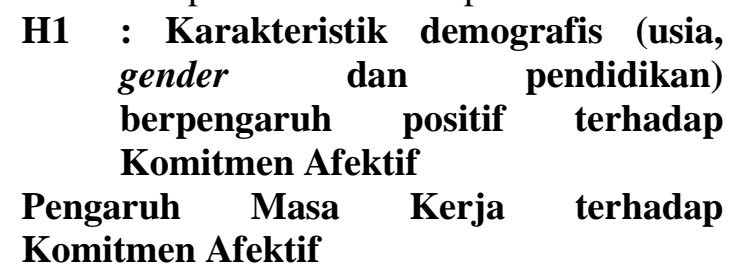

Masa kerja menjadi anteseden yang mempengaruhi komitmen afektif. Penelitan sebelumnnya menemukan bahwa pekerja yang memiliki waktu yang lama memiliki komitmen afektif yang tinggi kepada perusahaan jika dibandingkan dengan karyawan yang hanya memiliki masa kerja yang masih sedikit (English., 2010). Beberapa penelitian sebelumnya (Parks dkk., 1998; Kaur dan Sandhu, 2010; Popoola, 2009) menemukan bahwa masa kerja berhubungan positif terhadap komitmen afektif.

Berdasarkan beberapa penelitian yang dilakukan tersebut, maka penulis mengajukan hipotesis sebagai berikut:

\section{H2 : Masa kerja berpengaruh positif terhadap Komitmen Afektif}

\section{Pengaruh Kepuasan Gaji terhadap Komitmen Afektif}

Penelitian sebelumnya menemukan hubungan yang positif antara kepuasan terhadap gaji dengan komitmen afektif (Loscocco, 1990; Mottaz, 1988). Selain itu, penelitian Newman dan Sheikh (2012) menunjukan hubungan yang positif signifikan terhadap komitmen afektif karyawan dalam organisasi.

Berdasarkan hasil dan pernyataan penelitian sebelumnya, maka peneliti mengajukan hipotesis sebagai berikut:

\section{H3 : Kepuasan gaji berpengaruh positif terhadap Komitmen Afektif}

\section{KERANGKA PEMIKIRAN TEORITIS DAN PERUMUSAN HIPOTESIS}

Berdasarkan pemikiran terdahulu, maka dapat disusun kerangka pemikiran sebagai berikut:

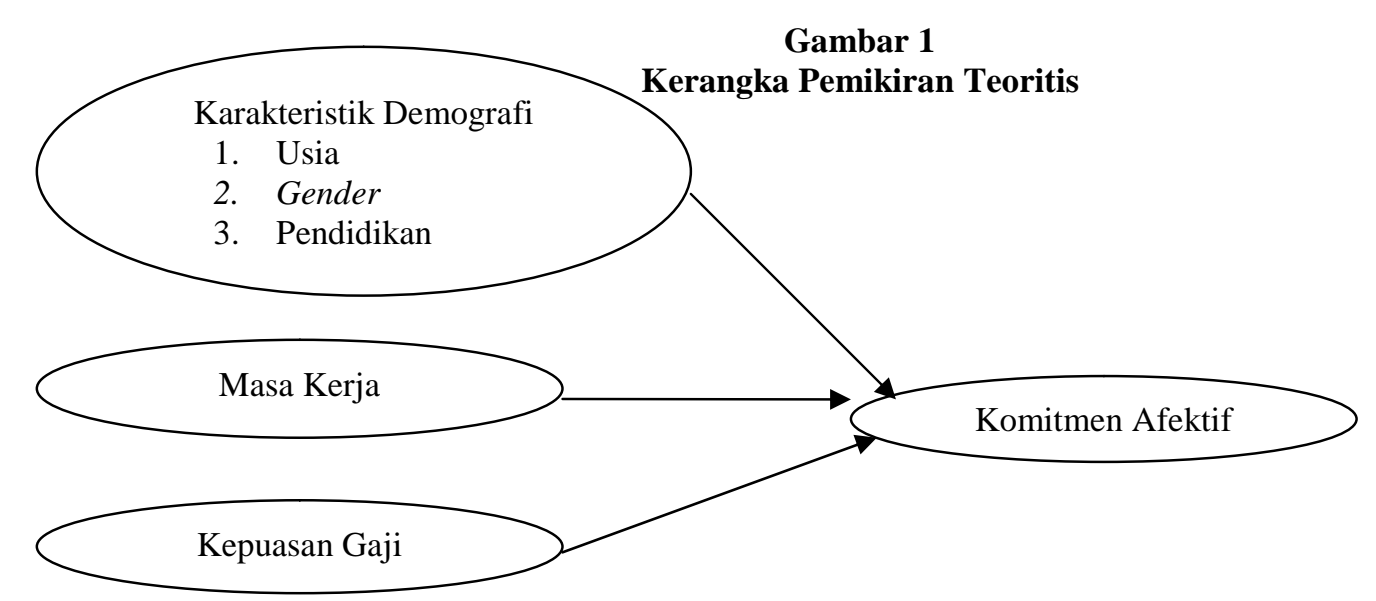

Sumber: (Ogba, 2008), Pentareddy dan Suganthi (2015), Popoola (2009), Yi-Ching Chen dkk (2012), Parks dkk (1998), Kaur dan Sandhu (2010), Newman dan Sheikh (2012), English dkk (2010), Yew (2008) 
Sehubungan dengan pernyataan kerangka teoritis diatas, maka diuraikan hipotesis dalam penelitian ini yaitu:

H1 : Karakteristik demografi berpengaruh positif terhadap komitmen afektif

$\mathrm{H} 2$ : Masa kerja berpengaruh positif terhadap komitmen afektif

H3 : Kepuasan gaji berpengaruh positif terhadap komitmen afektif

\section{METODE PENELITIAN Variabel Penelitian}

Penelitian menggunakan lima variabel yang diantaranya; variabel independen terdiri dari: usia, gender, pendidikan, masa kerja dan kepuasan gaji sedangkan variabel dependennya adalah komitmen afektif.

\section{Penentuan Populasi dan Sampel}

Adapun yang menjadi populasi dalam penelitian ini adalah tenaga paramedik NonPNS RSUD Kota Semarang yang terdiri dari dokter dan perawat yang tidak berstatus pegawai negeri sipil (tenaga paramedik kontrak) berjumlah 270 pegawai. Teknik penggunaan sampel dengan menggunakan metode purposive sampling. Tahap selanjutnya adalah menentukan jumlah sampel dari populasi yang ada.

Adapun penentuan total sampel dengan menggunakan teori perhitungan pendekatan Yamane (1973) dan besar kesalahan yang masih dapat ditoleransi sebesar 0,1. Adapun rumusnya adalah

$\mathrm{n}=\frac{N}{1+N d^{2}}=\frac{270}{1+270(0,1)^{2}}=\frac{270}{3,7}=73$

Keterangan:

$\mathrm{n}=73$ Responden ; $\mathrm{N}=$ Ukuran Populasi; $\mathrm{n}=$ Ukuran Sampel

$\mathrm{e}=$ margin of error, kesalahan ditoleransi $10 \%$

Jenis data yang digunakan yaitu:

1. Data subyek dalam penelitian ini yaitu berupa kuesioner dan wawancara

2. Data dalam bentuk dokumen dalam penelitian berupa data demografis karyawan

Dalam penelitian ini, peneliti menggunakan sumber data primer dan sekunder. Peneliti memperoleh data langsung dari sumbernya yaitu RSUD Kota Semarang melalui wawancara dan kuesioner sedangkan data sekunder yang digunakan berupa dokumentasi data struktur organisasi, data demografis dan foto struktur organisasi.

\section{Metode Analisis Data}

Metode Analisis yang digunakan dalam penelitian adalah analisis kuantitatif. Teknik pengolahan data kuantitati antara lain; editing, coding dan tabulating.

Penelitian ini menggunakan metode analisis data menggunakan aplikasi software SPSS versi 21. Dalam penelitian ini analisis angka indeks dilakukan untuk mengetahui kecenderungan jawaban responden terhadap indikator yang membentuk konstruk. Selain itu, penelitian juga menggunakan measurement untuk melihat kevalidan dan tingkat realibilitas kuesioner serta analisis regresi untuk melihat pengaruh antar variabel yang bersangkutan. Sebelum melakukan analisis regresi, data terlebih dahulu diuji asumsi klasik dan harus memenuhi syarat uji asumsi klasik. Uji asumsi klasik terdiri dari uji normalitas, uji heteroskedastisitas dan uji multikolinearitas. Selain itu, penelitian ini menggunakan uji lain yaitu uji hipotesis dan uji determinasi dalam mengukur variabel dependennya.

Setelah dilakukan uji asumsi klasik, kemudian dilakukan analisis regresi berganda terhadap model penelitian. Analisis regresi berganda digunakan untuk menguji pengaruh dua atau lebih variabel independen terhadap variabel dependen. Persamaan untuk menguji hipotesis secara keseluruhan pada penelitian ini adalah sebagai berikut:

$\mathrm{Y}=\mathrm{a}+\mathrm{b} 1 \mathrm{X} 1$ Implementasi $+\mathrm{b} 2 \mathrm{X} 1$ Stabilisasi +b3X1 Gender + b4X1 DIII + b5X1 S1+ b6X2 Early Tenure + b7X2 Middle tenure + b8X3 Kepuasan Gaji + e

Keterangan:

$\mathrm{Y}=$ Komitmen afektif

$\mathrm{a}=$ Konstanta

X1 = Karakteristik Demografis (Usia, Gender dan Pendidikan)

$\mathrm{X} 2$ = Masa Kerja

X3 = Kepuasan Gaji

b1, b2 , b3, dan seterusnya $=$ Koefisien Arah

Regresi

$\mathrm{e}=$ Error/variabel pengganggu 
HASIL PENELITIAN DAN

PEMBAHASAN

Analisis Angka Indeks

Berdasarkan perhitungan terhadap variabel

kepuasan gaji, ditemukan hasil tanggapan terhadap kepuasan gaji dapat dijelaskan pada tabel 1 dibawah ini:

Tabel 1

\begin{tabular}{|c|c|c|c|}
\hline No. & Item & $\begin{array}{c}\text { Nilai } \\
\text { Indeks }\end{array}$ & Kategori \\
\hline 1. & $\begin{array}{l}\text { Gaji yang saya dapatkan cukup dan sebanding } \\
\text { dengan kerja keras saya selama bekerja di Rumah } \\
\text { Sakit }\end{array}$ & 51,8 & Sedang \\
\hline 2. & $\begin{array}{l}\text { Besarnya kompensasi yang diberikan Rumah Sakit } \\
\text { sesuai dengan harapan saya }\end{array}$ & 50,8 & Sedang \\
\hline 3. & $\begin{array}{l}\text { Peningkatan besarnya upah yang saya terima } \\
\text { sudah sesuai dengan lama kerja saya di Rumah } \\
\text { Sakit selama ini }\end{array}$ & 52,4 & Sedang \\
\hline 4. & $\begin{array}{l}\text { Rumah Sakit sudah mengatur pemberian gaji } \\
\text { (sistem gaji) dengan baik dan adil }\end{array}$ & 55,2 & Tinggi \\
\hline & Jumlah & 210,2 & \\
\hline & Rata-rata & 52,55 & Sedang \\
\hline
\end{tabular}

Sumber: Data primer yang diolah, 2016

Analisis deskripsi terkait hasil tanggapan responden atas variabel Komitmen afektif dijelaskan pada tabel 2 dibawah ini:

Tabel 2

\begin{tabular}{|c|c|c|c|}
\hline No. & Item & $\begin{array}{c}\text { Nilai } \\
\text { Indeks }\end{array}$ & Skala \\
\hline 1. & $\begin{array}{l}\text { Saya akan sangat senang dapat menghabiskan sisa } \\
\text { karir saya di Rumah Sakit ini }\end{array}$ & 60,6 & Tinggi \\
\hline 2. & $\begin{array}{l}\text { Saya merasa masalah yang dihadapi Rumah Sakit } \\
\text { adalah masalah saya juga }\end{array}$ & 54,6 & Sedang \\
\hline 3. & $\begin{array}{l}\text { Saya merasa bahwa orang orang di RS seperti } \\
\text { keluarga sendiri }\end{array}$ & 60,2 & Tinggi \\
\hline 4. & $\begin{array}{l}\text { Secara emosional saya merasa sangat menyatu } \\
\text { dengan Rumah Sakit }\end{array}$ & 58 & Tinggi \\
\hline 5. & Rumah Sakit memiliki makna mendalam bagi saya & 58,2 & Tinggi \\
\hline 6. & $\begin{array}{l}\text { Saya merasa bahwa saya adalah bagian dari } \\
\text { Rumah Sakit }\end{array}$ & 61,4 & Tinggi \\
\hline & Jumlah & 353 & \\
\hline & Rata-rata & $\mathbf{5 8 , 8}$ & Tinggi \\
\hline
\end{tabular}

Sumber: Data primer yang diolah,2016 


\section{MEASUREMENT}

\section{Uji validitas}

Uji validitas digunakan untuk mengukur sah atau valid tidaknya suatu kuesioner. Suatu kuesioner dikatakan valid jika pertanyaan pada kuesioner mampu untuk mengungkapkan sesuatu yang akan diukur oleh kuesioner tersebut. Dalam penelitian ini mempunyai koefisien korelasi yang lebih besar dari $r$ tabel $=0,227$ (nilai $r$ tabel untuk $\mathrm{n}=75$ atau $\mathrm{df}=73$, diperoleh dengan rumus $\mathrm{df}=\mathrm{n}-2$ ). Sehingga semua indikator tersebut adalah valid. Adapun Pengujian validitas selengkapnya dapat dilihat pada tabel berikut ini:

Tabel 3

\begin{tabular}{lllll}
\hline No & Variabel / Indikator & Korelasi & r tabel & Keterangan \\
\hline 1 & Kepuasan Gaji & & & \\
& $\mathrm{X}_{5} .1$ & 0.882 & 0,227 & Valid \\
& $\mathrm{X}_{5} .2$ & 0.883 & 0,227 & Valid \\
& $\mathrm{X}_{5.3}$ & 0.850 & 0,227 & Valid \\
& $\mathrm{X}_{5.4}$ & 0.923 & 0,227 & Valid \\
\hline 2 & Komitmen Afektif & & & \\
& Y.1 & 0.767 & 0,227 & Valid \\
& Y.2 & 0.821 & 0,227 & Valid \\
& Y.3 & 0.827 & 0,227 & Valid \\
& Y.4 & 0.823 & 0,227 & Valid \\
& Y.5 & 0.806 & 0,227 & Valid \\
& Y.6 & 0.790 & 0,227 & Valid \\
\hline
\end{tabular}

Sumber: Data primer yang diolah, 2016

\section{Uji Realibilitas}

Uji reliabilitas digunakan untuk mengukur suatu kuesioner yang merupakan indikator dari variabel atau konstruk. Dikatakan reliabel karena memberikan nilai Cronbach Alpha > 0.70 (Ghozali, 2011). Adapun hasil uji reliabilitas dibawah ini menunjukkan bahwa semua variabel mempunyai koefisien Alpha yang cukup besar yaitu diatas 0,70 sehingga dapat dikatakan semua konsep pengukur masingmasing variabel dari kuesioner adalah reliabel.

Hasil pengujian reliabilitas untuk masing-masing variabel yang diringkas pada tabel 4 berikut ini:

Tabel 4

\begin{tabular}{lll}
\hline Variabel & Alpha & Keterangan \\
\hline Kepuasan Gaji & 0,907 & Reliabel \\
Komitmen Afektif & 0,895 & Reliabel \\
\hline
\end{tabular}

Sumber: Data primer yang diolah, 2016

\section{Uji Asumsi Klasik dan Regresi Berganda}

Uji asumsi klasik yang dilakukan pada penelitian ini terdiri atas uji normalitas, uji multikolonieritas, dan uji heteroskedastisitas. Dari seluruh uji asumsi klasik yang telah dilakukan, dapat disimpulkan bahwa:
Uji normalitas dengan uji kolmogorovsmirnov menunjukkan nilai probabilitas sebesar 0,196. Dengan nilai probabilitas yang lebih dari 0,05 maka dapat disimpulkan bahwa residual data penelitian terdistribusi secara normal. 
Uji multikoliniearitas menunjukkan nilai tollerance masing-masing variabel yang lebih besar dari 0,10 serta nilai VIF masing-masing variabel yang tidak lebih dari 10. Berdasarkan hasil tersebut, dapat disimpulkan bahwa tidak terdapat multikolonieritas pada model regresi penelitian ini.

Uji heteroskedastisitas dengan grafik scatterplot menunjukkan persebaran titik-titik pada grafik yang tidak menunjukkan pola tertentu. Dengan demikian, data-data penelitian ini heteroskedastisitas atau memiliki nilai variance yang berbeda.

Uji analisis regresi berganda. Analisis regresi berganda yang telah dilakukan diperoleh koefisien regresi, nilai t hitung dan tingkat signifikansi sebagaimana ditampilkan pada Tabel 5 dibawah ini:

Tabel 5

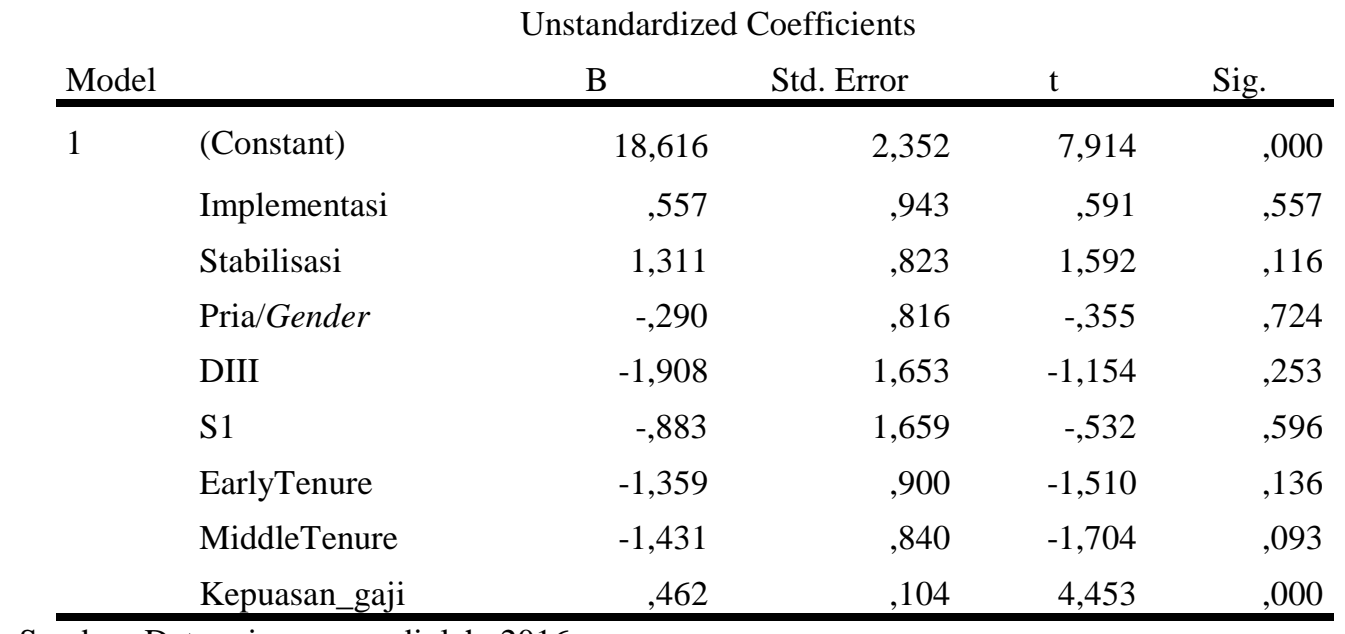

Sumber: Data primer yang diolah, 2016

Adapun persamaan regresi berganda dalam penelitian ini, dapat dilihat dalam persamaan berikut ini:

$\mathrm{KA}=18,616+0,557$ Implementasi $+1,311$ Stabilisasi - 0,29 Pria - 1,908 DIII - 0,883 S1 - 1,359 Early Tenure - 1,431 Middle Tenure + 0,462 Kepuasan Gaji

Uji Hipotesis

Uji Signifikansi Simultan (Statistik F)

Uji statistik $F$ akan menunjukkan apakah semua variabel independen yaitu usia, gender, pendidikan, dan masa kerja memiliki pengaruh secara bersama-sama terhadap variabel dependen yaitu komitmen afektif karyawan paramedik RSUD. Uji statistik F dalam penelitian ini dilakukan dengan melihat tabel ANOVA, dengan tingkat signifikansi yang digunakan adalah sig.< 0,05 . Hasil uji statistik F dapat dilihat sebagai berikut:

\begin{tabular}{|c|c|c|c|c|c|c|}
\hline \multicolumn{7}{|c|}{ ANOVA $^{a}$} \\
\hline Model & & Sum of Squares & $\mathrm{df}$ & Mean Square & $\mathrm{F}$ & Sig. \\
\hline \multirow[t]{3}{*}{1} & Regression & 285,934 & 8 & 35,742 & 5,280 &, $000^{b}$ \\
\hline & Residual & 446,733 & 66 & 6,769 & & \\
\hline & Total & 732,667 & 74 & & & \\
\hline
\end{tabular}

Tabel 6

a. Dependent Variable: Komitmen_afektif

b. Predictors: (Constant), Kepuasan_gaji, MiddleTenure, Pria, S1, Implementasi, Stabilisasi, EarlyTenure, DIII

Sumber: Data primer yang diolah, 2016 
Berdasarkan tabel 4.7 diperoleh nilai Fhitung sebesar 6,370 dengan tingkat signifikansi 0,000. Karena F hitung $(5,280)>$ F tabel $(2,34)$ dan memiliki nilai probabilitas signifikansi $(0,000)<0,05$ maka dapat disimpulkan bahwa semua variabel independen yaitu usia, gender, pendidikan, dan masa kerja secara simultan mempunyai pengaruh yang signifikan terhadap variabel dependen (komitmen afektif).

\section{Uji Signifikansi Parameter individual (Uji statistik t)}

Uji t digunakan untuk membuktikan apakah variabel usia, gender, pendidikan, dan masa kerja secara parsial/individu mempunyai pengaruh terhadap komitmen afektif. Uji ini dilakukan dengan membandingkan thitung dengan ttabel atau dengan melihat kolom $\mathrm{p}$ (sig.) pada masingmasing thitung.

Tabel 7

\begin{tabular}{rlrr} 
Model & & \multicolumn{1}{c}{ T } & Sig. \\
\hline 1 & (Constant) & 7,914 &, 000 \\
& Implementasi &, 591 &, 557 \\
& Stabilisasi & 1,592 &, 116 \\
& Pria/Gender &,- 355 &, 724 \\
& DIII & $-1,154$ &, 253 \\
& S1 &,- 532 &, 596 \\
& EarlyTenure & $-1,510$ &, 136 \\
& MiddleTenure & $-1,704$ &, 093 \\
& Kepuasan_gaji & 4,453 &, 000 \\
\hline
\end{tabular}

Sumber: Data primer yang diolah, 2016

Berdasarkan hasil uji signifikansi secara parsial, hanya kepuasan gaji yang menunjukkan hasil yang signifikan. Hal ini berarti hanya variabel kepuasan gaji yang mempengaruhi variabel dependen komitmen afektif sedangkan ketiga variabel lainnya tidak berpengaruh terhadap komitmen afektif.

\section{Uji Koefisien Determinasi}

Koefisien determinasi (R ) pada intinya mengukur seberapa jauh kemampuan model dalam menerangkan variasi variabel dependen. Nilai koefisien determinasi adalah antara nol dan satu (Ghozali, 2011). Nilai koefisien determinasi dapat dilihat pada Tabel 8 di bawah ini :

Tabel 8

\begin{tabular}{|c|c|c|c|}
\hline Model & $\mathbf{R}$ & R Square & $\begin{array}{c}\text { Adjusted R } \\
\text { Square }\end{array}$ \\
\hline 1 &, $625^{\mathrm{a}}$ & ,390 & ,316 \\
\hline
\end{tabular}

Hasil analisis menunjukkan bahwa nilai Adjusted $\mathrm{R}$ Square adalah sebesar 0,316. Dari hasil tersebut dapat disimpulkan bahwa kemampuan variabel-variabel independen yaitu usia, pendidikan, gender, masa kerja dan kepuasan gaji dalam menjelaskan variasi pada variabel dependen komitmen afektif adalah sebesar 31,6\% dan sisanya sebesar $68,4 \%$ dipengaruhi oleh variabel lain.
Hasil Pengujian Hipotesis

Pengaruh Usia terhadap Komitmen Afektif

Berdasarkan hasil penelitian, analisis pengujian hipotesis (H1) membuktikan bahwa koefisien regresi pengaruh variabel usia terhadap komitmen afektif diperoleh hasil sebesar 0,557 usia implementasi dan 1,311 usia stabilisasi. Nilai koefisien regresi tersebut memberikan makna bahwa usia 
memiliki hubungan positif. Hasil pengujian hipotesis menghasilkan nilai t hitung sebesar 0,$591 ; 1,592$ untuk implementasi dan stabilisasi dengan nilai signifikansi $=0,557$; $0,116>0,05$. Nilai signifikansi yang lebih besar dari 0,05 menunjukkan bahwa usia memiliki pengaruh positif namun tidak signifikan terhadap komitmen afektif.

Hasil ini juga sesuai dengan penelitian terdahulu yang dilakukan oleh Yi-Ching Chen dkk (2012) yang membuktikan dan menyimpulkan bahwa usia tidak berpengaruh signifikan terhadap komitmen afektif, dimana dikatakan tidak terdapat perbedaan komitmen afektif yang diperlihatkan oleh pekerja berusia kategori muda, menengah dan tua. Dalam penelitian ini juga memperlihatkan pola yang sama dimana tidak terdapat hubungan yang signifikan antara kedua variabel tersebut. Sehingga dengan begitu dapat disimpulkan bahwa hipotesis 1 (usia) penelitian ini ditolak.

\section{Pengaruh Gender terhadap Komitmen Afektif}

Berdasarkan hasil penelitian, analisis pengujian hipotesis (H1) membuktikan bahwa koefisien regresi pengaruh variabel gender terhadap komitmen afektif diperoleh hasil sebesar -0,290. Nilai koefisien regresi tersebut memberikan makna bahwa gender memiliki hubungan negatif. Hasil pengujian hipotesis menghasilkan nilai $\mathrm{t}$ hitung $\mathrm{t}=$ 0,355 dengan probabilitas $=0,724>0,05$. Nilai signifikansi yang lebih besar dari 0,05 menunjukkan bahwa gender memiliki pengaruh negatif dan tidak signifikan terhadap komitmen afektif.

Hasil ini juga sesuai dengan penelitian terdahulu yang dilakukan oleh Pentareddy dan Suganthi (2015) yang membuktikan dan menyimpulkan bahwa gender tidak berpengaruh signifikan terhadap komitmen afektif, dimana dikatakan tidak terdapat perbedaan komitmen afektif yang diperlihatkan oleh pekerja bejenis kelamin pria dan wanita. Dalam penelitian ini juga memperlihatkan pola yang sama dimana tidak terdapat hubungan yang signifikan antara kedua variabel tersebut. Sehingga dengan begitu dapat disimpulkan bahwa hipotesis 1 (gender) penelitian ini ditolak. Pengaruh Pendidikan terhadap Komitmen Afektif
Berdasarkan hasil penelitian, analisis pengujian hipotesis (H1) membuktikan bahwa koefisien regresi pengaruh variabel pendidikan terhadap komitmen afektif diperoleh hasil sebesar $-1,908$ pendidikan DIII dan $-0,883$ pendidikan S1. Nilai koefisien regresi tersebut memberikan makna bahwa pendidikan memiliki hubungan negatif. Hasil pengujian hipotesis menghasilkan nilai t hitung sebesar -1,154; 0,532 untuk DIII dan S1 dengan probabilitas 0,$253 ; 0,596>0,05$. Nilai signifikansi yang lebih besar dari 0,05 menunjukkan bahwa pendidikan memiliki pengaruh negatif dan tidak signifikan terhadap komitmen afektif.

Hasil ini juga sesuai dengan penelitian terdahulu yang dilakukan oleh Mathieu and Hamel, 1989; Steers (1977) dalam Yi-Ching Chen dkk., (2012) yang membuktikan dan menyimpulkan bahwa pendidikan tidak berpengaruh signifikan terhadap komitmen afektif, dimana dikatakan tidak terdapat perbedaan komitmen afektif yang diperlihatkan oleh pekerja/karyawan berpendidikan reguler dan tinggi. Dalam penelitian ini juga memperlihatkan pola yang sama dimana tidak terdapat hubungan yang signifikan antara kedua variabel tersebut. Sehingga dengan begitu dapat disimpulkan bahwa hipotesis 1 (pendidikan) penelitian ini ditolak.

\section{Pengaruh Masa Kerja terhadap Komitmen Afektif}

Berdasarkan hasil penelitian, analisis pengujian hipotesis (H2) membuktikan bahwa koefisien regresi pengaruh variabel masa kerja terhadap komitmen afektif diperoleh hasil sebesar -1,359 early tenure dan -1,431 middle tenure. Nilai koefisien regresi tersebut memberikan makna bahwa masa kerja memiliki hubungan negatif. Hasil pengujian hipotesis menghasilkan nilai $\mathrm{t}$ hitung sebesar -1,510; -1,704 untuk early tenure dan middle tenure dengan probabilitas 0,$136 ; 0,093>0,05$. Nilai signifikansi yang lebih besar dari 0,05 menunjukkan bahwa masa kerja memiliki pengaruh negatif dan tidak signifikan terhadap komitmen afektif.

Hasil ini juga sesuai dengan penelitian terdahulu yang dilakukan oleh Mathieu and Hamel, 1989; Steers (1977) dalam Yi-Ching Chen dkk., (2012) yang membuktikan dan menyimpulkan bahwa masa kerja tidak berpengaruh signifikan terhadap komitmen 
afektif, dimana dikatakan tidak terdapat perbedaan komitmen afektif yang diperlihatkan oleh pekerja/karyawan yang bekerja lebih lama dibandingkan pekerja yang baru bekerja di RSUD Kota Semarang. Dalam penelitian ini juga memperlihatkan pola yang sama dimana tidak terdapat hubungan yang signifikan antara kedua variabel tersebut. Sehingga dengan begitu dapat disimpulkan bahwa hipotesis 2 (masa kerja) penelitian ini ditolak.

\section{Pengaruh Kepuasan Gaji terhadap Komitmen Afektif}

Berdasarkan hasil penelitian, analisis pengujian hipotesis (H3) membuktikan bahwa koefisien regresi pengaruh variabel kepuasan gaji terhadap komitmen afektif diperoleh hasil sebesar 0,462. Nilai koefisien regresi tersebut memberikan makna bahwa masa kerja memiliki hubungan positif. Hasil pengujian hipotesis menghasilkan nilai $\mathrm{t}$ hitung sebesar 4,453 untuk dengan probabilitas $0,000<0,05$. Nilai signifikansi yang lebih kecil dari 0,05 menunjukkan bahwa kepuasan gaji memiliki pengaruh positif dan signifikan terhadap komitmen afektif.

Hasil ini juga sesuai dengan penelitian terdahulu yang dilakukan oleh Loscocco, 1990; Mottaz, 1988 yang membuktikan dan menyimpulkan bahwa kepuasan gaji signifikan terhadap komitmen afektif, dimana dikatakan semakin tinggi kepuasan akan memperlihatkan komitmen terhadap organisasi dengan berkurangnya turnover karyawan. Dalam penelitian ini juga memperlihatkan pola yang sama dimana terdapat hubungan yang signifikan positif antara kedua variabel tersebut. Sehingga dengan begitu dapat disimpulkan bahwa hipotesis 3 (kepuasan gaji) penelitian ini diterima.

\section{KESIMPULAN}

Pertama, tidak terdapat pengaruh variabel usia terhadap komitmen afektif karyawan RSUD Kota Semarang. Dalam arti lain, tidak terdapat perbedaan komitmen afektif yang diperlihatkan oleh pekerja berusia kategori muda, menengah dan tua. Kedua, variabel gender juga tidak memperlihatkan adanya hubungan yang signifikan terhadap komitmen afektif karyawan RSUD Kota Semarang, yang berarti tidak terdapat perbedaan komitmen afektif yang ditunjukkan oleh karyawan pria dan wanita

Ketiga, Variabel pendidikan karyawan tidak memperlihatkan adanya hubungan yang signifikan terhadap komitmen afektif karyawan RSUD Kota Semarang, yang berarti tidak terdapat hubungan antara tingginya pendidikan yang ditempuh terhadap komitmen pegawai paramedik RSUD Kota Semarang. Keempat, Masa kerja tidak menunjukkan adanya hubungan yang signifikan, tidak terdapat pengaruh lamanya karyawan bekerja terhadap komitmen afektif yang diberikan terhadap RSUD Kota Semarang.

Kelima, kepuasan gaji memperlihatkan hasil yang berbeda dengan variabel sebelumnya, yaitu kepuasan gaji memiliki hubungan yang positif dan signifikan terhadap komitmen afektif. Semakin tinggi kepuasan akan memperlihatkan komitmen terhadap organisasi dengan berkurangnya turnover karyawan.

\section{AGENDA PENELITIAN AKAN DATANG}

Adapun yang dapat menjadi agenda penelitian untuk dilakukan dalam penelitian selanjutnya:

1. Penelitian lebih lanjut mengenai komitmen afektif diluar faktor karakteristik demografi, masa kerja dan kepuasan gaji dikarenakan variabel ini hanya dapat menjelaskan $31,6 \%$ komitmen afektif.Berdasarkan hasil jawaban responden berkaitan dengan variabel komitmen organisasi secara keseluruhan menunjukan tingkat komitmen yang tinggi.

2. Perlu untuk melakukan penelitian ini diluar instansi rumah sakit, dikarenakan penyebaran gender terhadap pegawai paramedik kebanyakan wanita terkhusus RSUD Kota Semarang, yang kemungkinan dapat mempengaruhi tingkat signifikansi penelitian.

3. Menambah sampel penelitian, terutama apabila menggunakan variabel dummy. Karena tingkat signifikansi penelitian variabel dummy kemungkinan dipengaruhi oleh jumlah sampel.

4. Menambahkan pertanyaan terbuka untuk dapat menjelaskan komitmen afektif lebih terperinci. 


\section{REFERENSI}

Boles, J., Madupalli, R., Rutherford, B., Andy, J., \& Boles, J. (2007). The relationship of facets of salesperson job satisfaction with affective organizational commitment. http://doi.org/10.1108/08858620710773440

Brown, B. (2003). Employees' organizational commitment and their perception of supervisors' relations-oriented and task-oriented leadership behaviors. Leadership, 1-107

Coertse, S., dan Schepers, J. M. (2004). Some personality and cognitive correlates of career maturity. SA Journal of Industrial Psychology, 30(2), 56-73. http://doi.org/10.4102/ sajip.v30i2.150

Chan, S. C. H., dan Mak, W. M. (2014). Transformational leadership, pride in being a follower of the leader and organizational commitment. Leadership dan Organization Development Journal, 35(8), 674-690. http://doi.org/10.1108/lodj-12-09-0076

Darja, M. S. (1999). An empirical Test of Meyer and Allen's Three-Component Model of Organizational Commitment in a Crotian Context. Review of Psychology.

Dixit, D. V., dan Bhati, M. M. (2012). A Study about Employee Commitment and its impact on Sustained Productivity in Indian Auto-Component Industry. European Journal of Business and Social Sciences, Vol., 1(6), 34-51.

English, B., Morrison, D., dan (English, Morrison, dan Chalon, 2010), C. (2010). Moderator effects of organizational tenure on the relationship between psychological climate and Affective Commitment. Journal of Management Development, 29(4), 394-408. http://doi.org/10.1108/02621711011039187

Ferdinand, Augusty. 2014. Metode Penelitian Manajemen Edisi 5. Semarang : Badan Penerbit Universitas Diponegoro

Ghozali, Imam. 2011. Aplikasi Analisis Multivariate Dengan Program SPSS Edisi 7. Semarang : BP Universitas Diponegoro

Gikopoulou, N. (Ed. . (2008). Report on Effective Career Guidance

Gujarati, Damodar N. dan Dawn C. Porter. 2010. Dasar-dasar Ekonometrika Edisi 5.Jakarta: Salemba Empat.

Han, S. T., Nugroho, A., Kartika, E. W., dan Kaihatu, T. S. (2011). Perceived Organizational Support Dan Kepuasan Kerja.

Heneman, H., dan Schwab, D. (1985). Pay Satisfaction: It's Multidimensional Nature and Measurement. International Journal of Psychology, 20(2), 129-141. http://doi.org/10.1080/ 00207598508247727

Hian Chye Koh and, dan Boo, E. H. Y. (2004). Organisational ethics and employee satisfaction and commitment. http://doi.org/10.1108/00251740410538514

Jaros, S. (2007). Meyer and Allen Model of Organizational Commitment : Measurement Issues. The Icfai Journal of Organizational Behavior, 6(4), 7-26.

Jeung, Baek-Kyoo. (2012). The effects of core self-evaluations and transformational leadership on organizational commitment. Leadership dan Organization Development Journal, Vol. 33(6), $564-582$

Kantor, R. L. (2013). Pay Satisfaction , Organisational Commitment , Voluntary Turnover Intention, and Attitudes to Money in a South African Context ., (March).

Kaur, K., dan Sandhu, H. S. (2010). Career stage in organizational commitment: Empirical evidence from Indian banking industry. International Journal of Business and Management, 5(12), 141-152.

K. Sejjaaka, S., dan K. Kaawaase, T. (2014). Professionalism, rewards, job satisfaction and organizational commitment amongst accounting professionals in Uganda. Journal of Accounting in Emerging Economies, 4(2), 134-157. http://doi.org/10.1108/JAEE-01-2012-0003

Lamastro, V. (1999). Commitment and Perceived Organizational Support. National Forum of Applied Educational Research Journal, 12(3), 1-13.

Lewandowski, C. M. The Investment Model and Organizational Commitment: Predicting Workplace Behaviors, 1 Haverford College (2015). http://doi.org/10.1017/CBO9781107 415324.004 
Li, P., Fin, S., dan Razak, Z. (2013). Gender and Work : Assessment and Application of Super' s Theory - Career Maturity. British Journal of Arts and Social Sciences, 2(1995), 36-42. http://doi.org/10.11648/j.pbs.20130202.12

Liu, C. (2006). The early employment influences of sales representatives on the development of organizational commitment. Employee Relations, 29(1), 5-15. http://doi.org/10.1108/014254507 10714441

Lumbanraja, P. (2009). Pengaruh Karakteristik Individu, Gaya Kepemimpinan dan Budaya Organisasi terhadap Kepuasan Kerja dan Komitmen Organisasi (Studi pada Pemerintah Daerah di Provinsi Sumatera Utara). DIKTI, 7(NO. 43/DIKTI/KEP/2008 ISSN: 1693-5241)

Maulia, Shelly (2014). Pengaruh Usia, Pengalaman dan Pendidikan Dewan Komisaris terhadap Kualitas Laporan Keuangan.Skripsi.Semarang : Fakultas Ekonomika dan Bisnis, Universitas Diponegoro.

Mosse, J. C. (1993). Half the World, Half a Chance. Retrieved from http://shirky.com/writings/ half_the_world.html

Moser, C. O. N. (1993). Gender Planning and Development: Theory, Practice and Training. Feminist Review. http://doi.org/10.2307/1395333

Newman, A., dan Sheikh, A. Z. (2012). Organizational rewards and employee commitment: a Chinese study. Journal of Managerial Psychology, 27(1), 71-89. http://doi.org/10.1108/ 02683941211193866

Ogba, I. (2008). Commitment in the workplace. Management Research News, 31(11), 867-878. http://doi.org/10.1108/01409170810913051

Parks, D. J., Dawson, C. M., Morgan, S. D., Parson, S. R., Yakimowski, M. E., dan Hawkins, W. D. (1998). Predictors Of Affective Organizational Commitment Among High School Principals by Wilbert D . Hawkins Submitted to the Faculty of the Virginia Polytechnic Institute and State University in partial fulfillment of the requirements for the degree of DOCTOR

Pentareddy, S., dan Suganthi, L. (2015). Building Affective Commitment through job characteristics, leadership and empowerment. Journal of Management dan Organization, 21(03), 307-320. http://doi.org/10.1017/jmo.2014.93

Popoola, S. O. (2009). Organizational commitment of records management personnel in Nigerian private universities. Records Management Journal, 19(3), 204-217. http://doi.org/10.1108/09565690910999193

Rousseau, V., dan Aubé, C. (2010). Social support at work and Affective Commitment to the organization: the moderating effect of job resource adequacy and ambient conditions. The Journal of Social Psychology, 150(4), 321-340. http://doi.org/10.1080/00224540903365380

Sekaran, Uma. 2007. Research Methods For Business Metodologi Penelitian untuk Bisnis edisi 4. Jakarta : Salemba Empat

Serap, B., dan Harun, S. (2013). The analysis of demographic and work life variables which affect the occupational commitment of nurses. Journal of Management Development, 32(4), 419-434. http://doi.org/10.1108/026217113 11326392

Suhanto, E. (2009). Pengaruh Stress Kerja dan Iklim Organisasi terhadap Turnover Intention dengan Kepuasan Kerja sebagai Variabel Intervening (Studi di Bank Internasional Indonesia), $1-130$.

The World Bank, 2005. Pembangunan Berspektif Gender : Melalui Kesetaraan, Gender dalam Hak, Sumber Daya, dan Aspirasi. Jakarta : Dian Rakyat.

Unesco. (2004). The importance of good quality: What research tells us. Education for All: The Quality Imperative, 40-78. Retrieved from http://www.unesco.org/education/gmr_download/ chapter2.pdf

Wang, Shuhong., D. Caldwell, S., dan Yi, Xiang. (2015). The effects of education and allocentrism on organizational commitment in Chinese companies. International Journal of Manpower, 36, 754-771. http://dx.doi.org/10.1108/IJM-10-2013-022

W. Lam, L., dan Liu, Y. (2014). The identity-based explanation of Affective Commitment. Journal of Managerial Psychology, 29(3), 321-340. http://doi.org/10.1108/JMP-02-2012-0036 
Williamson, I. O., Burnett, M. F., dan Bartol, K. M. (2009). The interactive effect of collectivism and organizational rewards on affective organizational commitment. Cross Cultural Management: An International Journal, 16, 28-43. http://doi.org/10.1108/13527600910930022

Y. McCallum, S., L. Forret, M., dan Wolff, H.-G. (2014). Internal and external networking behavior. Career Development International, 19, 595-614. http://doi.org/10.1108/CDI-082013-0101

Yew, L. T. (2008). Job satisfaction and Affective Commitment: a study of employees in the tourism industry in Sarawak, Malaysia. World Review of Entrepreneurship, Management and Sustainable Development, 4(1), 85. http://doi.org/10.1504/WREMSD.2008.016210

Yi-Ching Chen, M., Shui Wang, Y., dan Sun, V. (2012). Intellectual capital and organizational commitment. Personnel Review, 41(3), 321-339. http://doi.org/10.1108/00483481211212968

Yousef, D. A. (2000). Organizational commitment and job satisfaction as predictors of attitudes toward organizational change in a non-western setting. http://doi.org/10.1108/00483480010 296401

Yousef, D. A. (2002). Job satisfaction as a mediator of the relationship between role stressors and organizational commitment A study from an Arabic cultural. http://doi.org/10.1108/0268394 0210428074 